\title{
HITZAURREA
}

\section{Politika, logika eta maitasuna}

DOI: $10.1387 /$ gogoa.20356

Polizia-sirenak lozorrotik esnatu zuen Jesus Mari. Nire baitako pentsamendu isiletik atera ninduen ni. Sirena-hotsak eta megafonia bidezkoa zirudien ahots ulertezin batek. Argi gorriak eta urdinak zerabiltzan polizia-autoak. Atzerako ispiluan ikus nitzakeen imintzioen arabera, bide bazterrera egiteko esaten zuen poliziak. Halaxe egin nuen, zintzo. Polizia bakarra zen. Eguzkitako betaurreko handien atzean hurbildu zitzaidan gidariaren leihatilara. Filmetan bezala, badakizue. Ez zen fikziozkoa, ordea. Benetako polizia zen.

Paperak eskatu zizkigun, eta errieta egin zigun abiadura mugatik gora -oso gora, sobrare- ibiltzeagatik. Kontu larria omen zen hori. Epailearen aurrera eraman behar gintuela esan zigun, eta harekin joan beharko genuela, baina, larunbata izanda, astelehena arte ziegan itxaron beharko geniola epaileari. Polizia guztiek beti eragin izan didaten urduritasuna eragin zidan ertzain hollywoodiar hark ere, eta ez nuen sumatu txantxetan ari zenik.

Ez dakit esaten Jesus Marik txantxa harrapatu ote zion —ez da sekula izan umorea eta ironia erraz harrapatzen dituenetakoa-, baina ez zen harekin eztabaida bizian hasi. Eskertu nion orduan, eta, egia esan behar badut, beste hainbatetan ere eskertuko niokeen. «Historikoak» dira Jesus Marik espainiar estatuko poliziekin (polizia, guardia zibil, ertzain nahiz munizipalekin) nahiz frantziar estatukoekin izandako ika-mikak; batzuetan bakarrik, beste batzuetan lagunekin. Ondoan tokatuz gero, Jesus Marirenganako miresmena baino handiagoa izaten zen arrisku-usainak eragindako dardara, nire kasuan behintzat.

Kontua da, sekula ordainduko ez genuela ondo jakin arren, isuna jarri eta aurrera egiten utzi zigula Kaliforniako freeway patrol hark. Renotik gindoazen, Joseba Zulaika antropologoari bisita labur bat eginda, presaka bueltan Palo Altora, Anita Burdman Fefermanek Jean van Heijenoorti buruzko liburuaren aurkezpena egin behar baitzuen iluntzean California Avenueko liburu-dendan. Azkenean, ez ginen liburu-dendara arrimatu. Berandu genbiltzan edo hala iruditu zitzaidan niri. Jesus Mariri seguru asko ez —denboraz 
eta puntual ibiltzeaz hark duen nozioa eta nik daukadana oso ezberdinak izan dira beti-. Kontua da hurrengo egunetan eskuratu genuela Burdman Feferman andreak sinatutako liburua Printers Inc. liburu-dendan: Politics, Logic, and Love.

Jean van Heijenoort izeneko logikariaren biografia da. ${ }^{1}$ Titulua irakurri orduko, iruditu zitzaidan Jesus Mariren bitzaren paraleloa izan zitekeela nolabait. Alde batetik, logikari —zehatzago esateko, ereduaren teoriari- eta, bestetik, politikari emandako bizitza izan zen Heijenoortena. Jesus Marirena ere bai. Beste alde batetik, logikarako eta matematikarako sekulako ahalmena izanda, konbentzimendu ideologiko kontsekuenteak zekarren militantzia politikoagatik konplikatu zitzaion bizitza Heijenoorti, Leo Trotskyren idazkari gisan. Jesus Marik ere euskal ezker abertzalean gaztetatik egindako militantziagatik, logikarako, matematikarako, filosofiarako eta ekonomiarako gaitasun jeniala bururaino eraman gabe utzi du seguru asko. Gainera, biek Frantzian ikasi zuten logika gaztetan, eta geroago Stanford Unibertsitatean logika lanetan ibili ziren bata zein bestea. Areago, badute beste antzekotasun bat ere: biek ezkerretik ekin zioten mundua aldatzen saiatzeari, eta biek galdu zituzten burkideak bortxa bidegabez. Horregatik, Heijenoorten bizitzaren deskripziorako nola, titulu egokia izan daiteke Jesus Marirenarentzako ere «Politika, logika eta maitasuna».2

Titulu egokia testu honentzako ere, nahiz eta biografia bat izan ez. Testu hau hitzaurre bat baino ez da, esku artean duzun Gogoaren ale berezi honen aurkezpena. Alea, osorik, Jesus Mari Larrazabal EHUko Logikako katedradun ohiari eskainia da, esker onez, bere 70. urtebetetzean opari, EHUtik erretiroa hartu eta urtebete pasatxora. Bestela esanda, akademian Festschrift esan ohi zaion hori da. Alearen egitura eta edukiak aurkezten hasi aurretik, hala ere, pertsona aurkeztea komeni da akaso.

Inork inoiz egin beharko luke biografia hori. Jesus Mariren bizitzak ematen du horretarako, dudarik ez dago. Inork idatzi beharko luke, bai; baina ez nik. Nik ezin dut. Hasteko, nik ez baitut Jesus Marik duen memoria, ezta hurrik eman ere. Eta haren ondoan urte asko egin ditudan arren, pasadizoak eta datak oker emango nituzke, eta gero Jesus Mariren kexak eta zuzenketak entzun beharko nituzke behin eta berriz. Gainera, opari hau isilpean gordetzen saiatu gara, eta ezin nintzen, beraz, bere bizitzari buruz galdezka ibili. Segidan kontatuko ditudanak erdizka eta oker esandakoak izango dira, hor-

1 Geroko edizioetan From Trotsky to Gödel jarri zioten titulua, Heijenoort berak atondutako From Frege to Gödel, logikarien artean ezaguna, gogoan, agidanez. Renotik Palo Altorako gure bidaia 1992. urtean izan zela uste dut, orain Burdman Fefermanen liburua lehen aldiz 1993an argitaratu zela irakurri arren.

2 1987an van Heijenoort Donostiara etortzekoa zen Jesus Marik gonbidatuta. Zoritxarrez, 1986ko martxoan hil egin zen. 
taz, xehetasunetan; baina funtsean egiazkoak direla uste dut, eta ziur nago gezurrik behintzat ez dagoela tartean, ezta bakar bat ere.

\section{Bio laburra}

Logikari zumaiarrak Jesus Maria Larrazabal Antia du grazia. Abenduaren 25ean jaiota, normala du «Jesus» hori, bistan denez; «Maria»k izango du esplikazioa garai hartako ohituretan, baina lagun estatubatuarren batek inoiz esan dion bezala, «Jose» —edo espiritu santua- bakarrik falta zaio familia sakratu osoa izenean eramateko. «Jesus Mari» edo «Jesusmari» da gehienontzat. Eta beste askorentzat «Tarzan»; militantzia politiko goiztiarrean ezagutu zutenentzat, bereziki. Horrek ere izango du esplikazioren bat. Ezizena jarri zionak jakingo ahal du. Nik behintzat Johnny Weismullerren antza handirik ez diot hartzen, eta ez diot inoiz hala esan. Baina aproposa iruditzen zait besteren ahotan «Tarzan» entzuten dudan bakoitzean. Agian, etsaiak ugari eta boteretsu izan dituen arren, haien kontra bakarrik edo bakar antzean egiteko izan duen eta oraindik duen gaitasunagatik izango da.

Txikitatik ezohiko gaitasunak zituen eta, orduko eskola-arau zurrunek halakorik nekez bideratzen bazuten ere, pasatu zuten pare bat maila aurrera, Tolosako eskolapioetara interno joan aurretik; ala ondoren, ez nago seguru. Han ez zuen bertako babarrunak jaten ikasi, baina etxean hazitako abertzaletasuna lantzen hasi zen, aztertzen, kritikatzen, sendotzen.

Ikasteko grina aseezina erakutsi zuen beti, eta etxetik Frantziara bidali zuten sistematikoki gaztetan, frantsesa ikas zezan. Baita ikasi ere. Ama-hizkuntza frantsesa zuela pentsa omen lezake jatorrizko frantses hiztunak. Ingelesa ikastera geroago bidali zuten Londresera, eta ahoskera atzerritarra utzi zion horrek hizkuntza horretan. Nolanahi ere, denboran lehentasuna izateak garrantzi-graduak igotzen dituelako edo, Frantziarekin izan du beti harremanik sakonena.

Han, Nanterren, 1968ko maiatzaren ondoko unibertsitatean ikasi zituen Ekonomia eta Filosofia. Promozioan lehena bukatu zuen ekonometrian, eta horrek lanpostu segurua esan nahi omen zuen Frantziako banku handienetako Parisko bulegoetan. Filosofia ere egitea hautatu zuen, eta filosofian logikan espezializatzea, eta ikerketarekin jarraitzeko AEBetara joateko aukerari muzin egin eta Euskal Herrira etortzea. Deustuko unibertsitateak Donostian duen campuserako gonbita jaso zuen, baina unibertsitate publikoa hobetsi zuen. Bergarako UNEDera etorri zen, eta Zorroagako UPV/EHUra. Bi horietan hasi zuen bere akademia-bizitzako urterik eta indarrik onenak hartuko zituen unibertsitate-lan konplexua. 1992an lortu zuen EHUko Logikako katedra. Filosofia Fakultateko dekanorde izan zen 1987tik 1989ra, Logika eta Zientziaren Filosofia Saileko zuzendari 1998tik 2001era, eta ILCLI institutuaren zuzendari 2008tik 2009ra. 2017an erretiratu zen. 
Unibertsitateko lanaz gain, militantzia politikoan oso engaiatua ibili da Jesus Mari oso gaztetatik, hainbat mugimendu eta alderditan; esate baterako, honako hauetan: Herri Gaztedi, LAIA, Herri Batasuna, Eusko Alkartasuna, Bildu eta EH Bildun. Horietan guztietan Jesus Marik izandako konpromisoaren tamaina ezaguna dute barruan dabiltzanek, baina, esango nuke, bestela, publikoki (mediatikoki, orain esango genukeen bezala), bere ibilera politikoa ez dela oso ezaguna, ez baita kargu publikoetan askorik ibili. Bitan izan zuen kargu publikoa. Gipuzkoako Foru Aldundiko diputatu izan zen, Franko hil ondoko lehen diputazioan, 1979-1983 bitartean, Herri Batasunako ordezkari gisa. Horrez gain, Euskal Autonomia Erkidegoko Legebiltzarkide, Lopez lehendakariaren garaian, 2009tik 2010era, Eusko Alkartasunaren izenean. Ez zion unibertsitateko eskolak emateari utzi ez diputatu ez legebiltzarkide gisa. 2010ean Legebiltzarra utzi behar izan zuen, osasun-arrazoiak zirela medio. Ez zuen, haatik, politika utzi. Eusko Alkartasunan eta EH Bildun segitzen du, unibertsitatetik erretiroa hartu ondoren ere. Filosofia eta poesia irakurtzeari eta idazteari ere ez diola utzi egingo nuke apustu.

\section{Logika}

Esan bezala, 1976an hasi zen Euskal Herrian unibertsitate-lanetan: Bergarako UNEDen 1981 arte, EHUn 1981etik 2017an erretiroa hartu zuen arte. Unibertsitategintza publikoak zor handia dauka harekin. Parte-hartze aktiboa izan zuen EHUko estatutuen idazkuntzan irakasleen egonkortasuna lortzeko, eta egituren sorreran. Gobernu-batzarreko kidea izan zen 1988tik 1991ra eta Gizarte Kontseiluko kidea 1990 eta 1991n. Ikerketa Batzordean, Erreklamazio Batzordean eta Argitalpen Kontseiluan ere aritu zen beste urte askoan. Hori bai, oposizioan beti. Oposizio publikoan. Agintean zegoen edozeini kontzesiorik batere egin gabe. Eztabaida publikoan gogorra, oso gogorra, izan daiteke arrazoirik erabiltzen ez duen edozeinekin. Sonatuak omen ziren, esate baterako, Emilio Barbera errektorearekin eta bere hainbat errektoreorderekin izandako sesioak. Amarruak egiteko, azpikeriatan ibiltzeko, ezintasun nabarmena du. Gorroto du iruzurra. Barberak galdetu omen zion behin bere errektoreorde eta Filosofiako fakultatekidea zen bati: «Nola eros dezaket Larrazabal?». Erantzun omen zion: «Ezin duzu. Ez du ezer behar. Dena galtzeko prest dago, arrazoiari uko egin, burua makurtu eta isilik geratu baino lehen». Errektoreorde hark egia esan zuen aldi bakarretakoa izango zen.

Jarrera horrek ez dio unibertsitate-bizitza erraztu. Hemendik gutxira haren merezimendu laurdenik ere ez duen bere adinkideren bat edo are gazteagoren bat ere ikusiko dugu fakultate bati, zentro bati edo unibertsitateko eraikin publiko bati izena ematen. Larrazabal edo Jesus Mari izenekorik nekez topatuko dugu inoiz. John Perryk eta biok 2011n argitaratutako liburu batean «Larrazabal Hall» esan genion EHUko alegiazko eraikin bati. Ez dakit oso ondo hartu zuen. Inork inoiz bere izena ezeri jarriko ba- 
lio, seguru esango lukeela, Arestiri oihartzun eginez, «Ez dut nahi inork esan dezan: ni Larrazabalen bizi naiz, anaiaren koinata nagusiarekin. Badakizu. Maingua.» Esku artean duzun hau ere ez dakit nola hartuko duen. Jesus Marik sekula ez du bilatu aitortza publikorik nahiz irabazi pribaturik, egin duen ezertan.

Unibertsitateari hainbeste urtetan eskainitako dedikazioan filosofia- eta logika-irakaskuntzaren maila eta zorroztasuna bermatzeak zuen lehentasuna; bere irakaskuntza serioa eta zorrotza zen, hasteko, eta halakoa izatea nahi zuen berak formatuko zituen irakasle gazteen eskutik. Hori egiteko ikertu egin behar du unibertsitate-irakasleak. Ikerketa duina egiteak nazioarteko sareetan parte hartzea eskatzen du, bestalde. Eta horrek ingelesa ezagutzea. Gehitu horri unibertsitate euskalduna eraikitzeko konpromisoa, eta Jesus Marik abiatutako lanaren tamaina irudikatzeko modua izan dezake batek: (1) irakaskuntza zorrotza, (2) nazioarte mailako ikerketa, (3) euskara, eta hori guztia (4) unibertsitate publikoan.

Beste askorekin partekatzen ditu helburutzar horiek, jakina. Aldarrikapen gisa euskal gizartearen gehiengo zabalak babesten dituela esatea ez da gehiegi esatea. Duela berrogei urte hasita egunerokoan horien alde lanean aritu direnak askoz gutxiago dira, ordea. 1980. urtearen bueltan izango zen, ziur asko, irakaskuntza maila gorena bilatzen zuen inor; baina, orduan, ikerkuntzaren garrantzia gutxietsiko zuen praktikan, edo euskararena. Euskaltzaleak ere ez zuen askotan estimu handian izango ingelesez egin beharreko ikerketa; edo, askok unibertsitate pribatuan izango zuen begia. Lehentasuna nazioarteko puntako ikerketan izan duten beste batzuek, aldiz, diru publikoz ondo hornitutako proiektu pribatuak egin dituzte, euskararen presentzia itxura hutsezkora mugatuz. Bestela esanda, eta labur, Jesus Mariz aparte, inork gutxik heldu die lau zutabeei batera, bakar bati ere uko egin gabe. Eta parekorik gabea bihurtu du horrek bere lana. Jesus Mari bakarrenetakoa izan da, bakarra agian, lau fronte horietan jarduten, eta jardunak praktikan bakardadera eraman du seguru asko. Ez du unibertsitateko arduradunen babesik izan, ez alderdi politiko edo sindikatuena, ez enpresena, ez komunikabideena, ez lobbyena, ez — hark esango lukeen bezala-mafia ezberdinena.

Hala eta guztiz ere, Bergarako UNEDen egituratzean oinarrizko lana egiten hasi zen 1976an Paristik Euskal Herrira itzuli orduko. EHUn, Leioan estatutuen diseinuan eta abarretan aritzeaz gain, Zorroagako Filosofia fakultatearen egituratzean ere zeregin garrantzitsua izan zuen, ez soilik Filosofia-ikasketak euskalduntzeko ahaleginean, baizik eta ke hutsala saltzen ziharduten orduko elpaiszale eta diariovascozale —eta, hala ere, Eginen babesa zuten - sasifilosofo haien aurrean, filosofia egiteko modu duina eta serioa bultzatzeko borroka latzean. Logika eta Zientziaren Filosofia sailaren egituratzean ere rol erabakigarria izan zuen, irakasle soil gisa hasieran, Logikako katedradun gisa gero, sailaren zuzendari gisa ere bai, baina, batez ere, irakasle 
berrien formakuntzan. Sekulako lana egin zuen saila osatzen eta are ikerketa-egitura berriak sortzen ere. Doktorego-programen, master-ikasketen eta lizentzia eta graduen diseinuetan parte hartu zuen buru-belarri. Logika, Kognizio, Hizkuntza eta Informaziorako Institutua sortu zuen -ILCLI, ingelesezko izenaren akronimoaren arabera-. (Gaur horrenbeste physics, culinary, eta abarren ondoan gezurra dirudi, baina unibertsitate-agintariek ez zioten utzi izena ofizialki ingelesez jartzen. Nahitaez elebiz behar omen zuen izenak. Logikagune proposatu balu, onartuko zioten akaso).

Bertatik bertara ezagutu zuen Stanford Unibertsitateko ikerketa-zentro batean inspiratuta, ILCLI institutua sortu zuen Jesus Marik. Eta, 1993ko abenduko sorrera ez-ofizialetik aurrera, horren osatze- eta egituratze-lanetan ibili behar izan zuen batik bat, filosofian eta kognizio-zientzietan eta, oro har, giza zientzietan mundu mailan ezaguna den ikerketa-zentro bat erdietsi arte. Euskara eta ingelesa ditu lan-hizkuntza eta bertako eta kanpoko ikertzaileak langile. Ez da erraza izan institutua maila horretara eraman eta hor mantentzea, beste behin, unibertsitate-agintarien babes eskasa izan duelako, eta, egiari zor, agintari askoren kontrako jarrera ere izan duelako; haiei galdetu beharko litzaieke zergatik. Gogoa aldizkari honen sorreran ere izan zen Jesus Mari, Xabier Arrazolarekin batera. Hasiera hura ere ez zen erraza izan.

Nolanahi ere den, egitura-sortzaile handia izan da Jesus Mari unibertsitatean. Baina, batez ere, irakasle izan da. Euskal unibertsitate publikoko filosofia-ikasleen orain arteko belaunaldi guztien irakasle ahaztezina. Ahaztu gabe geroko irakasle izango ginenon formatzaile erabakigarri gisa bete duen eginkizuna. Ikertzaile gisa doktorego-ikerketan estu hezi gintuen EHUko filosofia-irakasle izango ginenetako mordoxka bat (Arrazola zena, Arrieta, Carrascal, Migura, Pérez Miranda...). Filosofiakoak izango ez ziren batzuk ere bai, izan EHUkoak edo beste unibertsitate batekoak (Alonso, Ezenarro, Gómez Txurruka zena, Marín, Ulazia...), eta baita unibertsitatearekin lotura zuzenik gehiago izango ez zuten beste hainbat ere (Arranz, Marroquín, Iztueta...). Unibertsitate bat egitea irakasle-ikertzaileak heztea da nagusiki, eta Jesus Marik egin du bere zatia hor. Nahi eta nahi ez, onerako nahiz txarrerako - gogo onez eta harro batzuek, ez horrenbeste beste batzuek-, haren marka, haren zigilua, eramango dugu gure irakaskuntzan eta ikerkuntzan.

Ikertzaile gisa, van Heijenoortek bezala, logika izan du eremu nagusia: ereduen teoria esaten zaionaren alorrean egin zuen doktorego-tesia. Eta, ikasleak formatzearekin batera, logikaren aplikazioei jarri zien arreta. Logika arrazoitzearen azterketara aplikatua, edo hizkuntzaren estudio semantiko eta pragmatikora, edo gogo-egoeren azalpenera, edo adimen artifizialaren oinarrietara, aplikazio horietako batzuk besterik ez aipatzearrren. Bere lan propioen bidez baino besteokin batera egindako lanen bitartez eman ditu ezagutzera bere ikerketaren emaitzak, ikertzaile gazteok ingelesez eta nazioarteko aldizkarietan argitaratzera bultzatuz. 
Ekonomiaren alorrean, ez du irakaskuntza- edo ikerkuntza-lanik egin, tesinaz harago, nahiz eta erretiroa hartu aurreko urteetan buruan ibili duen gogoko ideia bat baino gehiago izan den Parisen doktoregoa egiten hastea. Oker ez banago, problema burokratikoek galarazi diote, azkenean, desioa asmo sendo bihurtzea.

Nire uste apalean, unibertsitateak, oro har, eta Euskal Herriko unibertsitate publikoak, zehatzago, azken 40 urteotan izan duen bilakaera kontuan hartuta, egindako lanak eta lortutako emaitzak alderatzen hasita, damutzeko arrazoi bat baino gehiago dauka Jesus Marik. Ikuspegi pertsonaletik, behintzat, ez dago dudarik. Egin duen unibertsitate-lanak osasuna itxuragabe kaltetu dio, kaltetu dionez, eta, hainbat lagunen aitortza pertsonalaz gain, ezer gutxi ekarri dio onik. Tira, gauza bat bai, esan dezake inork: gustukoen duena egiteko, irakurtzeko eta estudiatzeko denbora eman dio, soldata bat emanez. Bai, baina askoz unibertsitate hobeetan egin zezakeen hori, diru askoz gehiago irabaziz, eta, Jesus Marirentzat garrantzitsuago dena, irakurtzea eta estudiatzea sustatu baino, praktikan, eragotzi egiten duen unibertsitate sistema espainiarretik libre. Ziur nago inoiz - maiz, beharbada- pentsatu izan duela honen antzeko zerbait: «Logikaren ikerketarekin segitzeko AEBetara joan banintz, Keislerrek iradoki bezala? Edo, gutxienez, Parisen geratu izan banintz, edo beste inon, Euskal Herri demonio honetara, unibertsitate eskas honetara, bueltatu ordez?».

Hori pentsatu eta porrot-sentsazioa izan ote duen ere badaukat susmoa, nahiz eta agian damutu ez. Hau zioen 2004an egin zioten elkarrizketa interesgarrian:

Parisen, Nanterreko unibertsitatean ikasi nuen Ekonomia matematikoa. Promozioko lehenengoa izan nintzen, eta 1976an bi aukera etorri zitzaizkidan. Bat, Parisko Banku Nazionalean, BNPn, lan egitea. Bestea, AEBetara joatea, Logikako tesia egitera. Bankuari erraz eman nion ezetza, banekien ez nuela hor lan egin nahi. Baina kosta zitzaidan besteari ezezkoa ematea. Oso baldintza onak ziren, eta banekien hara joanez gero ez nintzela itzuliko. Hango unibertsitateren batean bukatuko nuen. Ezezkoa esan nuen, garbi nuelako Euskal Herrira itzuli behar nuela. Militantziaz, nire tokia hau delako eta ikasitakoa bertan egiteko. Jakina, hemen dauzkagun bitartekoekin. Hona etorri, eta zerotik hasi nintzen, logika ikasleak sortzen, ikasle horiek tesietara eramaten, eta tesia atera ondoren irakasle bihurtzen... (Eizagirre eta Eizagirre 2004)

Eta bukatzen du: «Erabaki sakon bezala sekula ez dut damu izan.»

«Erabaki sakon bezala», dio, ez zaio damutu. Baina, ez dakit ba. Militantziaz hartutako erabakia dela esaten du, Euskal Herrira itzuli behar zuela pentsatu zuelako, ikasitakoa Euskal Herrian egiteko. Unibertsitatearen bilakaerari erreparatuta, pentsa liteke gehiago egin ahal izango zuela euskal filosofo eta logikariak formatzen AEBtako unibertsitate puntakoren batetik, EHUtik 
baino. Atzerrian formazioaren zati bat behintzat egitea ezinbestekoa da gaur egun irakasle-ikertzaile duinak hezteko. Euskal ikasle mordoxka AEBetako unibertsitate on batean hartu eta haiekin jo ta ke aritzeak ez ziokeen galaraziko Jesus Mariri puntako ikerketa normal bat egitea, bere kasuan, mundu mailan lehen mailako filosofo eta logikari izatera eramango zuena; dudarik ez dago.

Batek daki. Erabakia berea izan zen. Eta militantziaz izan zen. Hori izan baita, eta da, Jesus Mariren bizitzaren bigarren ardatza: militantzia politikoa.

\section{Politika}

Ezkerrekoa eta independentziazalea. Hala deskriba daitezke Jesus Mariren bi ardatzak politikan. Sekula ez da bi ideia nagusi horietatik aldendu: Euskal Herriak estatu bat behar du, eta estatu horren antolaketak gizarte-justizian izan behar du oinarri. Bi ideia horiek akitu arte defenditu dituela esango nuke, Urola-Kostako Herri Gaztedin arduradun zenetik Eusko Alkartasunako Donostiako militante den garai hauetaraino. Ezkerrekoa eta independentista izateko bere modu propioa izan du beti, hala ere.

Estatua. Euskal abertzaleek ez dute beti estatua defenditu. Batzuek nahiago izan dute beti nazioaz hitz egin; autonomiaz, eta ez autodeterminazioaz eta independentziaz. Estatutuan zegoen etorkizuna, herrien Europan. Horiei nazionalista esaten die Jesus Marik, hitz hori abertzaleren gaztelaniazko itzulpen gisa baztertuz. Euskal alderdi nazionalista nagusian ikusten ditu abertzaleak, bai, baina bere politika autonomistetan ez. Iganderoko batzoki-inaugurazioetako hitzaldietan dira agintariak abertzale; egunerokoan, nazionalistak.

Hitzetik hortzera independentzia zerabilten askok ere estatu hitza baztertu izan dute maiz. Eta ernegatu egiten du horrek Jesus Mari. Independentzia aldarrikapena, estaturik gabe, edukiz zeharo husten dela uste du. Slogan huts bihurtzen dela. Euskal estatuaren sorrera izan da helburua beti Jesus Marirentzat. Euskaldun gehienon borondatean eta nahietan oinarritzen da nazioidentitatea. Nazioa gara eta estatu propioa sortu behar dugu. Eta kontzeptu horien oinarritze kontzeptual sendoaren zerbitzura jarri du beti bere formazio filosofiko, ekonomiko eta politikoa. Ez du sekula pazientzia handirik erakutsi kontzeptu politikoen nolanahiko erabilerarekin, eta sutan jarri da beti politikariek, nahita, herritarrei ziria sartzeko, ala nahi gabe, formazio eskasagatik, errealitatearen deskripzio okerrak egin dituzten bakoitzean. Beti salatu du hiritar edo herritar terminoak (ciudadano/a, gaztelaniaz; citoyen/ne, frantsesez) oso oker erabiltzen dituztela batzuek eta besteek. Hiritar kontzeptua estatu kontzeptuari lotua dago. Euskal hiritarrik ez dago, euskal estaturik gabe. Bitartean, hiritar gisa, (euskal-)espainiarrak edo (euskal-)frantsesak gara. Hala esan zien Eizagirre ahizpei: 
Jakina, estatu hori autonomietan antolatua badago, esan behar litzateke inolako karga ideologikorik gabe, errealitatea horixe delako, «ciudadan@s español@s-vasc@s»edo «ciudadan@s español@s-navarr@s». Baina «español» hitz hori ezin da disimulatu.

Liburuxka berdean [«Ibarretxe plana» delakoari dagokion testuan] oso interesgarria da aztertzea atariko tituluan zer estatus ematen zaion «Ciudadan@s vasc@s»horri. Zeren esatendu: «l@s ciudadan@s vasc@s tienen sus derechos y deberes que vienen de la constitución $»^{3}$ baina ez du esaten: «constitución española». Hori tranpa da. Kontzeptu politikoak erabili behar dira zuzen. Dagoena dago, eta nahi baduzu ez dagoena egotea, jarri egin behar duzu. (Eizagirre eta Eizagirre 2004)

Sozialismoa. Hitz hori ere edukiz hustearen kontrako jarrera sutsua erakutsi izan du beti. Esango nuke Herri Gaztediko garaietan ere, independentzia eta sozialismoarekin batera helburua iraultza erabatekoa zenean (alegia, maitasun eta sexu librea, Euskal Herri euskalduna, erlijioak kanpora esparru publikotik, arrazoian oinarritutako morala, emakumeak (eta gizonak) beren gorputzen jabe, hezkuntza publiko askatzailea, lan alienatzailearen eraldatzea, munduko herriekin elkartasuna, eta nik zer dakit ba), Jesus Marik analitikoki bereiziko zituzkeela auzi estrategikoak eta besteak. Azpiegiturari zegozkionak eta besteak; aldaketa iraultzailearen funtsari zegozkionak eta besteak. Ordukoak eta pixka bat geroagokoak dira nazio-auziaren eta klase-borrokaren auziaren uztartzeari buruzko eztabaidak Euskal Herrian. Eztabaida sutsuak nazionalista zaharren eta marxista gazteen artean; iraultzaile espainolista eta abertzale burges-txikien artean. Eztabaidak eta hausturak. Nazio-arazoa gizarte-analisi marxistarekin ezkontzeko lan dotorea egin zuten batzuek, ordea. Hori ere kontatu beharko dute historialariek, baina han irudikatzen dut Jesus Mari gaztea —Tarzan-, Mario Onaindia, Jokin Apalategi eta Argalarekin, besteak beste, testuak eta zirriborroak trukatzen eta formulazio honetaz eta hartaz eztabaidan. Nire irudikapen hutsa izango da lau horien arteko harremana, baina hirurei buruzko hitz onak, oso onak entzun izan dizkiot beti.

Sozialismoa Euskal Herrian gaur egun gauzatzea geoestrategikoki ezinezkoa dela esan izan du aspalditik. Arrazoi logistikoengatik Sobiet Batasunaren inguruarekin tratuan ibiltzeagatik ere atentzioa eman omen zion behin baino gehiagotan zegokionari. Kontua da, sozialismoa modu ekibokoan erabili ordez, nahiago izan duela askotan sozialdemokrazia aurreratuaz hitz egin. Neoliberalismoa etsai nagusi duen sozialdemokraziaz. Justizia soziala eta berdintasuna indibiduoen askatasunaren gainetik ezartzen duen sistema sozialaz. Ezin da benetako askatasunik izan indibiduoen arteko ezberdintasunean, injustizia sozialean, oinarritua.

\footnotetext{
3 Euskal hiritarrek beren eskubide eta betekizunak dituzte, konstituziotik datozenak.
} 
Sozialismoa Arizmendiarrietaren kooperatibismo katolikoarekin identifikatzeak ere bere onetik ateratzen du. Batetik, iruzur teoriko ikaragarritzat daukalako; ezjakintasunaren edo fedearen (fede txarraren) ondorio izan, langileak bere buruari iruzur egitera kondenatzen ditu. Bestetik, kezka handia eragiten diote kooperatibismoak euskal indar politikoetan duen penetrazioak eta horren ondorioek; hala nola, enpresa-interesetara makurtutako unibertsitateak bultzatzeak unibertsitate publikoaren kaltetan edo, garrantzitsuagoa dena, enpresa-eredu kooperatiboa zabaltzeak Euskal Herrirako eredu enpresarial ideal gisa. Eztabaida horri ekiteko indarra antzematen zaio oraindik ere.

Esango nuke, nolanahi ere, 1960ko hamarkadako belaunaldi haien ametsak ez zaizkiola ahaztu, eta, bere belaunaldiko askok bezala, porrot-sentipena duela, non gauden ikusita. Izan ere, urte gogorrak izan dira Euskal Herri independente eta sozialistaren aldeko militantzia politikoan ibili direnentzat. Jesus Mariri ere torturatu, kartzelatu eta hil dizkiote burkideak eta lagunak. Hori guztia zertarako? Gauden egoera honetara iristeko? Porrot-sentipena, halakorik baleuka, ulergarria litzateke.

Eztabaida-, zatiketa- eta borrokaren egituratze-urte haietako oroitzapenetan Argala eta Mario Onaindia aipatu izan dizkit maiz. Tristura eta miresmen puntu batekin aipatu ere. Beste batzuentzat oroitzapen eta hitz mingotsak zituen. Joan omen zen behin (ez naiz akordatzen ondo, baina beste norbaitekin uste dut) abertzaleen eta nazionalisten testuak argitaratzen zituzten fraide batzuengana Tolosara, Onaindiak kartzelan itzulitako Althusserren Pour Marx testuarekin, argitaratzeko eskatuz. Ezezko biribila jaso zuen. Ez zuen Jesus Marik erraz ahaztuko.

Esango nuke Jose Miguel Beñaran, «Argala», dela abertzaleen artean ezagutu duen estatu-gizon edo, hobeto esan, estatu-pertsona bakarrenetakoa; akaso, Telesforo Monzonekin eta Karlos Garaikoetxearekin batera, ez dakit. Argalari buruz hitz bereziak izan ditu beti. Berezko gaitasun politiko aparta ikusten ziola esango nuke, antolakuntzarako gaitasun apartaz gain. Argia, zorrotza eta ausarta izateaz gain, sentibera omen zen, eta aitortzen omen zion min egiten ziotela bere kontra egiten zuten nazionalisten kritika maltzurrek, marxista izateagatik eta euskara behar bezala ez menderatzeagatik espainolista zela zioten haienek.

Jesus Marirengan ere sumatzen dira sentiberatasuna eta pasioa, adimenarekin batera. Eztabaida politikoan gogorra, oso gogorra izan daiteke - hala entzun diet Herri Gaztedin, LAIAn, Herri Batasunan, Eusko Alkartasunan nahiz Bildun ezagutu dutenei-, eta bere jarreren defentsak muturreraino eraman ditzake, haustura politikora iritsi arte (LAIAren zatiketan parte hartu zuen, LAIA BAIren alde; LAIAk KAS utzi zuen; Herri Batasunan ere hautsi zuen Gipuzkoako Diputazioan parte hartuz, hark udaletan salbu gainerako erakundeetan parte hartzeari uko egin zionean...), baina beti izan du gaitasuna, haustura politiko handien gainetik, harreman pertsonalari eusteko, 
pertsona estimatzen duenean behintzat. Horrez gain, bere diplomaziarako bokazioaren eraginez edo (bere benetako bokazioa horixe zela esaten zuen, eta gure estatu faltak zapuztu ziola beti; hari entzun nion lehen aldiz Euskal Herriko enbaxada New Yorken Nazio Batuen aurrean beretzat nahi zuela; Martxelo Otamendiri entzun diot gero), liskarrak baretu eta adostasunak bilatzeko joera izaten zuen behintzat.

Grazia handiz kontatzen du, Zarautzen, Herri Batasunaren mahai nazionalaren bileran, Telesforo Monzon HB uztear izan zenekoa. Ez dut ondo gogoan programa politiko orokorra zen edo hauteskunde jakin batzuetarako prestatzen ari ziren programa zen, baina garai hartako Herri Batasunaren ideiak modu sistematikoan eta ordenatuan paperean jartzea omen zen kontua. Pelaje ezberdinetako pertsonak biltzen ziren han: militante zaharrak eta gazteak, alderdi politiko handi eta batez ere txiki askotako ordezkariak, ezkerrekoak eta eskuinekoagoak, seminarista izateari utzi berriak eta ateo porrokatuak, alkateen mugimenduko jauntxo txikiak, futbolari ezagun independenteak... eta horien artean, tente eta dotore, Telesforo Monzon. Telesforo omen zen kolektibo desorekatu hartan batasunari eusteko giltza, eta hura pozik uzten saiatu behar omen zuten batasunaren beharra ikusten zutenek. Tentuz ibili omen ziren testua Telesfororen begietan sozialistegi, laikoegi edo aurreratuegi izan ez zedin. Eta dena ondo omen zihoan «emakumeak beren gorputzen jabe» edo horrelako zerbait irakurri zuen arte. Sutan jarri omen zen Monzon. Bazekiela ondo zer esan nahi zuen horrek. «Abortua! Abortua esan nahi du horrek!»; eta ezetz, berak ez zuela hori inolaz ere onartuko. Altxatuko zela mahai hartatik, hori onartu baino lehen. Feministek, altxatzeko orduan, beraiek ez baitzuten puntu hori erretiratuko, eta, kentzen bazen, bazihoazela beraiek. Jesus Marik-eta beren diplomazia-dohain guztiak erabili behar izan omen zituzten, bilera hura hausturan ez bukatzeko. Hura zen Telesfororen marra gorria.

Bitxia iruditu izan zaigu beti, bai Jesus Mariri bai niri, politikari kristauek duten marra gorria. Alderdiari edo nazioari dioten leialtasuna aipatzen dute, edo «hau politika da, badakizu» moduko aitzakiak, beren ustezko ideologia propioaren kontra bozkatu behar dutenean. «Nik ez nuen horren aldeko (edo kontrako) botoa eman nahi, baina...». Beste herrialde batean pertsonak hilko dituzten armak saltzearen aldeko botoa gaur, milaka langile kalera botako dituen erreformaren aldekoa bihar, euskara bigarren mailako hizkuntza izatera kondenatzen duen legearen aldekoa etzi, eta nahi duzun guztia, salbuespen bakar batekin: abortua. Hori azaldu orduko, kontzientzia aipatuko dute, eta beste ezeren gainetik jarri. Kontzientzia kasu horretan soilik inposatzen zaio arrazoi politikoari kristauen kasuan. Bitxia.

Desadostasunak desadostasun, saiatu da Jesus Mari aurreko belaunaldiarekiko zubi-lanak egiten, Telesforo Monzonekin eta Larrazabal aitak eta haren gisako gudari zaharrek estimuan zituzten abertzale haiekin. Politikan 
bezala, unibertsitategintzan eta euskal kulturan ere, oro har, saiatu da zubi horiek egiten: Karlos Santamariarekin, esate baterako. Eta, hura bezala, hurrengo belaunaldiekin katea ez etetearen premiaz jabetzen da. «Gazteek beti arrazoi» da horren harira errepikatzen duen leloetako bat; ez beti arrazoia dutela uste duelako, ez horixe. Aurrera egingo dutenak gazteak direla garbi daukalako, eta lehentasuna haiekin lotura gordetzea delako; zertan ari diren jakin eta, ahal denean, laguntzea.

Gertutik ezagutu dugunok azpimarratuko genukeena ez da, ordea, Jesus Mari filosofo, logikari eta ekonomialari jakintsua edo Jesus Mari politikari eta militantea. Apustu egingo nuke, galtzeko batere beldurrik gabe, Jesus Mari pertsona izan dela guztioi, ezeren gainetik lehen egunetik, atentzioa eman diguna. Jesus Mari pertsona, edo pertsonaia.

\section{Maitasuna}

Ezagutzen dugun guztiok gogoratzen dugu, nik uste, Jesus Mari ezagutu genuen eguna. Arrastoa utzi zigun, seguru. Hitz-jario handikoa da. Harropuntu batez jantzia. Hizkuntzaren araberakoa izan daiteke, baina gaztelaniaz edo frantsesez ezagutu duenak pedante samartzat har dezake agian. Ingelesez ezagutu dutenek bortitzegitzat, akaso. ${ }^{4}$ Inor gutxi utziko zuen hotz edo epel, sikiera. Ezohiko adimenaz gain, ezohiko pasioa, ezohiko jenioa antzematen zitzaion berehala.

Pasioa jartzen dio egiten duen edozeri: eskola ematen ari zela, azalpen bakoitzari, proposizio txiki nahiz teorema handiaren demostrazio bakoitzari; bilera akademikoan nahiz politikoan, eztabaidagai den puntu bakoitzari. Logika, matematika eta zientzia formalak, oro har, pasioei kontrajarrita ikusten dituzten guztiek kontra-adibide garbia daukate berarengan. Logika eta poesia ez dira elkarren etsai. Logikaren ederra pasioz transmititzeko gai da Jesus Mari.

Jenio ikaragarria ere ezagutu diogu. Jenioa, hitzaren bi adiera nagusietan. Jenio bizia du; txarra, alegia. Inor izutzeko modukoa. Arrazoia izanda ere (eta gehienetan arrazoia duela esango nuke) arrazoia galarazten diona askotan. Logikako eskoletan arbelera ateratzen gintuenean sentitzen zen presioak malkoetara eraman zuen bat baino gehiago. Jenioa ateratzean, ordea, ez zuen, beste askok bezala, ahulen, berdinen eta indartsuen arteko diskriminaziorik egiten. Sekulako ika-mika izan dezake ertzain, jendarme edo guardia zibilarekin, horiek izutzeko adina, baina, batez ere, gertu geundenak ikara-

\footnotetext{
${ }^{4}$ Seguru asko Jesus Mari ez da bat etorriko honekin, bere ustez maila berean hitz egiten baititu hizkuntza horiek guztiak; Eusko Legebiltzarreko bere fitxan datorrena berak uste duena baldin bada, behintzat: «Idiomas: Euskera, Castellano, Francés, Inglés (todas al mismo nivel)» (http:// www.legebiltzarra.eus/fichas/c_652_SM.html, 2018ko irailaren 27an ikusia.)
} 
tzeko modukoa. Batzuetan egoera komikoak sortzen zituen horrela, eta askotan bera izaten zen kaltetu nagusia.

Ondo gogoan dut 2002an John Perry Stanford Unibertsitateko irakaslea EHUko Doctor Honoris Causa izendatzearen harira Leioako Errektorearen bulegoan izan zuen kalapita. Manuel Montero zen errektore orduan, eta bere bulegotik eskatua zioten Jesus Mariri ekitaldian egingo zuen laudatioaren testua aurretik bidaltzeko. Jesus Marik ez zien bidaltzen, eta egitarauan berari egokitutako denbora laburtzen zihoan egitarau ofizialean. Goiz hartan errektoreak bulegoan hartu eta campusean arbola landatzera laguntzea zen egitaraua, eta bulegoan mokadu bat jatea, ez dakit arbola landatu aurretik edo ondoren. Perry eta bere emazte Frenchie, Stanford Unibertsitateko provost John Etchemendy eta bere emazte Nancy, Logika saileko zuzendari Xabier Arrazola eta nirekin joan zen Jesus Mari. Hasieran Monteroren akolitoek bulegotik kanpo utzi gintuzten Arrazola eta biok, auskalo zein protokolo-arrazoirengatik. Ez zuen zentzu handirik, Monteroren ingelesak bere euskarak baino existentzia txikiagoa baitzuen, itxura guztien arabera.

Sartzera gonbidatu gintuztenerako Montero eta Jesus Mari ika-mikan hasiak zeuden, pintxoz betetako mahai baten ondoan. Lau estatubatuarrak ondoko gelatxoan zain zeuzkaten. Monteroren aldetik Murua errektoreordea gogoratzen dudala uste dut, eta protokoloaz arduratzen zen emakumea. Ezbaiaren bolumena igotzen hasi zen. «Ez nauzu zentsuratuko» zioen batak; «bertan behera utziko dugu dena» besteak. Ibarretxe zen garai hartan lehendakaria, eta bere plana bultzatzen ari zen, abertzale gehienen babes kritikoarekin. Montero euskal alderdi sozialistaren alde anti-abertzaleenaren ordezkaria zen, EHUko hainbat irakasle bezala bizkartzainez inguratuta ibiltzen zena, ETAren ustezko mehatxuengatik. Jesus Marik zer esango zuen beldur zen Montero, agidanez. Ibarretxeren planaren alde egingo ote zuen edo nik zer dakit ba; baina Jesus Mariren hitzaldia kontrolatu nahi zuela zirudien. Eta hori ezinezkoa da. Auskalo zer norabide hartu zuen eztabaidak. Auskalo. Batak ez zuen bestea erraz isilduko. Eta eztabaidak luze jo zuen.

Bitartean, amerikarrak ezer ulertu ezinik, Arrazola eta biok zer esan asmatu ezinda. Pintxo batzuk eta ardo pixka bat ekarri genuen beste gelara, baina liskarra gero eta handiagoa, gero eta ozenagoa zen. Egun hartan formek galdu zituzten bata zein bestea. Monterok amerikarren aurrean emandako irudia ezin txarragoa, hori bai. EHUko arduradun nagusiak irudi instituzional barregarria erakutsi zuen, beste ezer ez esateagatik, John Perry eta batez ere John Etchemendyren aurrean, Stanford Unibertsitateko arduradun akademiko (eta praktikan ekonomiko) nagusi zenaren aurrean. Egun batzuk geroago ikasturtearen irekitze-ekitaldia eta Honoris Causaren izendapen-ekitaldia ondo joan zen. Jesus Marik, Perryk, Monterok eta Ibarretxek beren hitzaldiak egin zituzten eta ez zen ezer apartekorik gertatu. Hori bai, Monterok bertan behera utzi zuen egitarauan zegoen Saltillo ontzian egiteko itsas bi- 
daia, eta Arzak jatetxeko afaria ez zuen bertan behera utzi, baina bera ez zen agertu (ni joan nintzen bere ordez, gaitz-erdi), eta unibertsitateak ez dio sekula ordaindu Jesus Mariri afariaren gastu hura.

Jesus Marirekin harremana izan duenak, bietako bat: hura gorroto du ala maite du, baina ez dago tarteko biderik. Barrea eragiten du, edo malkoa, edo serio demonio aritu beharra, baina ez dago harekin azalkeriatan edo arinkeriatan ibiltzerik. Bitxia da Jesus Mari, eta berak badaki. «Zoratuta nagoela esango dute berriz» esaten du batzuetan, bere harro-puntu axolagabe, mespretxuzko, bereizgarri horrekin.

Jenioaren bigarren adierak ere, xx. mendeko filosofian Russelli nahiz Wittgensteini lotzen zaion jenio mota horrek, bazuen Jesus Marirengan presentzia. Adimen zorrotza, jakin-min amaigabea, oroimen miragarria, jakinduria itxuraz mugagabea... eta eguneroko bizitzaren xehetasun praktikoetarako ezgauza; beti presaka eta beti berandu, Wonderlandeko untxi zuriaren antzera.

«Zoro» maitagarritzat daukagunotako batzuek parte hartu dugu opari honetan. 70 urte beteko dituenean oparia egin nahi genion, gure aitorpen apal gisa, beti hiltzear dagoela esan digun jenio horrek beste 70 beteko dituen esperantzan, eta oparia marmarka hartuko duen segurantzian.

Erretiroa hartu berria den honetan, beste oparitxo hau ere egin nahi diot nik: Jesus Marik sinatzeko modukoa den beheko adierazpen hau. Ray Monk britainiarrak egina da, besteak beste Russellen eta Wittgensteinen biografia mardulen egilea den filosofoak, erretiroa hartzearekin batera. Ondo islatzen du filosofiak akademian azken berrogei urteetan zer bide egin duen:

«Lanbide batean hasi nintzen eta merkatu bat lagatzen ari naiz». ${ }^{5}$

Amen.

\section{Edukiak}

Alea hiru zati nagusitan banatu dugu. Lehenengoan, horrelako Festschrift batean ohikoa denez, artikuluak daude: logikakoak, hizkuntzaren filosofiakoak, pragmatikakoak, soziologiakoak, psikologiakoak, eta abarrekoak; ikasle ohiek, irakaskideek edo ikerketakideek esku artean dauzkaten ikerketa-lanak dira, Jesus Mariri maitasunez eskainiak. Euskaraz idatzi dituzte gehienek; eta ingelesez besteek. Bigarren zatian ohar pertsonal laburragoei egin diegu tokia. Badira unibertsitatez kanpoko lagun batzuenak ere, baina unibertsitatekoak dira gehienak, bestelako lagunek unibertsitateko aldizkari batean idazteko erreparoak tarteko.

\footnotetext{
${ }^{5}$ I joined a profession and I am leaving a market. Ray Monk, Facebook-en.
} 
Hirugarren zatian Jesus Marik egindako lanen zerrenda dakargu, Julen Zabalak osatua. Julenek egina izanda, osoa ere badela esango nuke; ez balitz, Jesus Marik testu asko sinatu gabe utzi dituelako seguruenik. Zerrendatutako guztiak bereak direla seguru.

Alean parte hartzeko, Jesus Marik egindako lagunen lagin txiki bat baino ez dugu lortu. Batzuk ez dira garaiz iritsi, beste batzuek gonbita ere ez zuten jasoko agian. Horientzat guztientzat, abisu bat: Gogoa irekia duzue Jesus Mariri buruzko zuen oharra edo harentzako opari zuen artikulua bidaltzeko.

Eta, bukatzeko, esker on ohar txiki bat parte hartu duten guztientzat, eta Ekain Garmendia, Joana Garmendia eta Larraitz Zubeldiarentzat beren itzulpenengatik. Esker bereziak Joanari eta Larraitzi, normalean baino lan gehiago egitea tokatu zaielako; are esker bereziagoak Larraitzi, Gogoan egiten duen ohiko lanari, ama berria izatearena eta niri ale hau atontzen laguntzearena gehitu baitizkio.

Bitartean, 70 bete dituzun honetan, zorionak eta urte askotarako, Jesus Mari!

\section{Erreferentzia bibliografikoak}

Burdman Feferman, Anita (1993). Politics, Logic and Love. The Life of Jean van Heijenoort. Natik, MA: AK Peters.

EIZAGIRRE, Estitxu eta EIZAGIRRE, Ixiar (2004). «Jesus Mari Larrazabal: "Gizartean zabaldu behar dena plazera da"». Argia, 2004ko otsailaren 8a (www.argia.eus-en azken aldiz 2018ko irailaren 27an ikusia).

Kepa Korta 